\title{
Mapping of functional brain activity in freely behaving rats during voluntary running using manganese-enhanced MRI: Implication for longitudinal studies
}

\author{
O. Eschenko ${ }^{a, *, 1}$, S. Canals ${ }^{\text {a,1,2 }}$, I. Simanova ${ }^{a, 3}$, M. Beyerlein a , Y. Murayama ${ }^{\text {a }}$, N.K. Logothetis ${ }^{\text {a,b }}$ \\ ${ }^{a}$ Max Planck Institute for Biological Cybernetics, Spemannstrasse 38, Tübingen D-72076, Germany \\ b Imaging Science and Biomedical Engineering University of Manchester, Manchester, UK
}

\section{A R T I C L E I N F O}

Article history:

Received 30 August 2009

Revised 28 October 2009

Accepted 29 October 2009

Available online 4 November 2009

\section{Keywords:}

Manganese

Toxicity

Brain mapping

MEMRI

Behavior

Rat

\begin{abstract}
A B S T R A C T
Magnetic resonance imaging (MRI) is widely used in basic and clinical research to map the structural and functional organization of the brain. An important need of MR research is for contrast agents that improve soft-tissue contrast, enable visualization of neuronal tracks, and enhance the capacity of MRI to provide functional information at different temporal scales. Unchelated manganese can be such an agent, and manganese-enhanced MRI (MEMRI) can potentially be an excellent technique for localization of brain activity (for review see Silva et al., 2004). Yet, the toxicity of manganese presents a major limitation for employing MEMRI in behavioral paradigms. We have tested systematically the voluntary wheel running behavior of rats after systemic application of $\mathrm{MnCl}_{2}$ in a dose range of $16-80 \mathrm{mg} / \mathrm{kg}$, which is commonly used in MEMRI studies. The results show a robust dose-dependent decrease in motor performance, which was accompanied by weight loss and decrease in food intake. The adverse effects lasted for up to 7 postinjection days. The lowest dose of $\mathrm{MnCl}_{2}(16 \mathrm{mg} / \mathrm{kg})$ produced minimal adverse effects, but was not sufficient for functional mapping. We have therefore evaluated an alternative method of manganese delivery via osmotic pumps, which provide a continuous and slow release of manganese. In contrast to a single systemic injection, the pump method did not produce any adverse locomotor effects, while achieving a cumulative concentration of manganese $(80 \mathrm{mg} / \mathrm{kg})$ sufficient for functional mapping. Thus, MEMRI with such an optimized manganese delivery that avoids toxic effects can be safely applied for longitudinal studies in behaving animals.
\end{abstract}

(c) 2009 Elsevier Inc. All rights reserved.
The mapping of whole-brain activity engaged in certain behaviors or cognitive processes using non-invasive imaging techniques is nowadays routinely used in humans. Such studies are now becoming feasible for non-human primates (Conway et al., 2007; Goense et al., 2008; Kayser et al., 2007; Maier et al., 2008; Op de Beeck et al., 2008), but still remain a challenge for application in alert and behaving rodents, the most commonly used experimental animals. One reason for that is that the majority of behavioral paradigms developed for rodents often require active locomotion as a behavioral expression of a particular cognitive function. There exist conventional neuroimaging techniques that are routinely used in freely moving and behaving rodents, but most of them, e.g. 2-deoxyglucose autoradiography, c-fos immunohistochemistry require postmortem brain tissue processing to visualize the functional circuits that were activated during the task

\footnotetext{
* Corresponding author. Fax: +497071601652.

E-mail address: oxana.eschenko@tuebingen.mpg.de (O. Eschenko).

1 Authors contributed equally.

${ }^{2}$ Current address: Instituto de Neurociencias, Campus de San Juan, 03550 San Juan de Alicante, Alicante, Spain.

${ }^{3}$ Current address: Max Planck Institute for Psycholinguistics and Donders Institute for Brain, Cognition and Behaviour, Centre for Cognitive Neuroimaging, Nijmegen, The Netherlands.
}

at hand (Holschneider et al., 2003; Holschneider et al., 2006; Nguyen et al., 2004). They are therefore inadequate for longitudinal experiments investigating the development of certain behaviors or potential experience-induced reorganization of the brain's effective connectivity.

Non-invasive techniques can be used instead, by means of which localization of brain activity in vivo can be done at multiple time points (Palmer et al., 1999; Keilholz et al., 2006; Spenger et al., 2000). Yet, such techniques, e.g. functional magnetic resonance imaging (fMRI) or positron emission tomography (PET) are extremely sensitive to subject motion. Movement restriction in awake rodents or immobilization by means of anesthesia is possible but such strategies limit the application of the method to the simplest behaviors like sensory evoked responses and consequent mapping of sensory pathways (Keilholz et al., 2006; Van Camp et al., 2005; Weber et al., 2006). Thus, mapping of the whole-brain activity directly and, particularly, studying the reorganization of brain activity patterns over time in the same animal require further methodological developments.

Manganese-enhanced MRI (MEMRI) with systemically injected $\mathrm{MnCl}_{2}$ is a promising method that has been recently applied for functional brain imaging in non-restrained rodents (Berkowitz et al., 2006; Bissig and Berkowitz, 2009; Yu et al., 2005). MEMRI is - in 
general - predominantly used in animals due to a number of distinct features of manganese. For one, it can be used for the study of anatomical connectivity. Manganese injected locally is taken up by the cells, it can be transported to synaptic terminals, released into extracellular space and subsequently taken up again by other neurons, allowing tracing neural pathways (Canals et al., 2008; Pautler, 2004; Saleem et al., 2002; Watanabe et al., 2006; Watanabe et al., 2004). When administered systemically, $\mathrm{Mn}^{2+}$ reaches the brain and enters the cells via voltage-gated $\mathrm{Ca}^{2+}$ channels (Lee et al., 2005) to then be transferred trans-synaptically. Most importantly, because manganese's transfer is through voltage-gated channels and at relatively low rates, the accumulation of the substance inside cells as well as in the surrounding extracellular space is proportional to neural activity (Lin and Koretsky, 1997). The combination of these properties with the fact that the divalent $\mathrm{Mn}^{2+}$ is paramagnetic and reduces the longitudinal relaxation times (T1) of water protons, thereby resulting in enhanced signal intensity on T1-weighted MR images at the locations where $\mathrm{Mn}^{2+}$ accumulates (Silva et al., 2004), instigated the developing of many MEMRI applications including visualization of functional maps in freely moving animals (Bissig and Berkowitz, 2009; Yu et al., 2005).

Similar to other contrast agents, the concentration of $\mathrm{Mn}^{2+}$ in the brain needs to be sufficiently high to achieve better MR image contrast and signal-to-noise ratio (SNR). At the same time, manganese, being an essential metal microelement, is toxic in high concentrations; a fact that strongly limits the application of MEMRI method in behavioral paradigms. When injected systemically, only a small fraction of $\mathrm{Mn}^{2+}$ reaches the brain. Therefore, often the blood-brain barrier needs to be disrupted in order to make $\mathrm{Mn}^{2+}$ accessible to the brain for efficient detection by MRI (Aoki et al., 2004a; Silva et al., 2004), or alternatively relatively high concentrations of manganese are administered (Aoki et al., 2004b; Lee et al., 2005). Although MRI-detectable changes can be achieved with systemic doses as low as $9 \mathrm{mg} / \mathrm{kg}$ (Lee et al., 2005), much higher concentrations of manganese (up to $250 \mathrm{mg} / \mathrm{kg}$ ) are routinely used in many MEMRI studies as they result in substantially better spatial resolution of MR images (Silva et al., 2004).

At present, there seems to be no consensus among MRI investigators on a safe manganese usage in animals, and the concentrations of manganese are predominantly determined by a specific scientific question in a given study. Manganese doses that have been used for brain activity mapping in awake and behaving rodents (e.g. $66 \mathrm{mg} / \mathrm{kg}$ for rats and $64 \mathrm{mg} / \mathrm{kg}$ for mice) have been considered as non-toxic because they produced no or minimal side effects detected in rodent general behavior (Berkowitz et al., 2006; Berkowitz et al., 2007; Bissig and Berkowitz, 2009; Yu et al., 2005). Berkowitz and colleagues reported no retinal toxic effects after a single systemic injection of $\mathrm{MnCl}_{2}$ assessed by number of histological, physiological and electrophysiological indices (Berkowitz et al., 2006; Berkowitz et al., 2007). In our recent study, we found that corticohippocampal neurotransmission was weakened following $\mathrm{MnCl}_{2}$ acute systemic administration in a dose of $80 \mathrm{mg} / \mathrm{kg}$, while overall neuronal excitability and synaptic plasticity in the dentate gyrus of the hippocampal formation were not affected (Eschenko et al., in press). Complementary immunohistological examination revealed no signs of neuronal toxicity or glial reaction at the recording site.

This dose range, however, is likely to produce such adverse side effects as depressed general activity, somnolence, transient weight loss, skin irritation, bleeding or necrosis at the injection site (Bock et al., 2008a; Bock et al., 2008b; Silva et al., 2004). Differential sensitivity to manganese at cellular, physiological or behavioral levels is not surprising. It is known from toxicological literature that behavioral effects of manganese neurotoxicity may be present before any functional, structural or degenerative changes in the manganeseaffected brain regions (Gwiazda et al., 2007). Thus, the behavioral assessment of manganese acute toxicity may prove to be the most sensitive.
Evidently, application of MEMRI method for behavioral studies in rodents involving active locomotion or appetitive motivation currently may have serious limitations due to acute aversive effects induced by high concentrations of manganese commonly used for brain imaging. One obvious way to decrease manganese toxicity is to reduce the concentration of manganese injected, but decreasing manganese concentration makes detecting manganese-dependent changes in T1-weighted MR images more difficult (Silva et al., 2004). Compensating for a lower manganese concentration is technically challenging. For example, longer and/or repeated scans could increase the time of each imaging experiment and the physiological burden on each subject due to longer anesthesia. One possible way to decrease manganese toxicity while keeping MRI-detectable levels of the ion, is to avoid transient high concentrations by slowly infusing larger volumes of diluted manganese using, for instance, osmotic pumps (Canals et al., 2008). Also, fractionated MEMRI has been suggested as an improved method of systemic manganese delivery by means of repeated administration of relatively low $(30 \mathrm{mg} / \mathrm{kg})$ doses of manganese with $48 \mathrm{~h}$ interval between injections (Bock et al., 2008a). However, the behavioral consequences of different administration protocols have never been studied in detail.

In the present study, we tested the effects of a single systemic administration of $\mathrm{MnCl}_{2}$ in a dose range of $16-80 \mathrm{mg} / \mathrm{kg}$ on rat voluntary locomotor activity. We demonstrate a dose-dependent decrease of voluntary running, which was accompanied by weight loss and decrease in food intake. The adverse effects were found to be proportional to the dose of $\mathrm{MnCl}_{2}$ and lasted for up to seven postinjection days. The lowest dose of $\mathrm{MnCl}_{2}(16 \mathrm{mg} / \mathrm{kg})$ produced minimal adverse effects, but was not sufficient for MRI-detectable elevated accumulation of manganese in movement-related brain regions. In addition, we evaluated an alternative method of manganese delivery to the brain by means of chronically implanted (i.p.) osmotic pumps that provide a continuous and slow release of $\mathrm{MnCl}_{2}$ over 7 days. In contrast to a single systemic injection, manganese administration via osmotic pumps allowed avoiding acute toxic effects, while achieving cumulative concentration of $\mathrm{MnCl}_{2}(80 \mathrm{mg} / \mathrm{kg})$ sufficient for functional mapping.

\section{Methods}

Male Sprague-Dawley rats (250-300 g) were used in the present study. Rats were maintained on a $12 \mathrm{~h} \mathrm{light/dark} \mathrm{illumination} \mathrm{cycle,}$ housed in groups of four and had ad libitum access to food and water. All experimental procedures were approved by the local authorities (Regierungspraesidium) and were in full compliance with the guidelines of the European Communities Council Directive of 24 November 1986 (86/609/EEC) for the care and use of the laboratory animals.

\section{Voluntary running procedure}

The rats' voluntary running activity was tested in a clear polycarbonate cage $(48 \times 27 \times 22 \mathrm{~cm})$ equipped with free access to a stainless steel wheel (35 mm in diameter). A stainless steel wire lid incorporated a $500 \mathrm{ml}$ water bottle and a U-shaped food hopper for lab chow (Tecniplast ${ }^{\circledR}$, Italy). Each rat was tested individually and returned to the home cage after testing. During the entire testing period, the rat had free access to the running wheel, food and water. Rats' voluntary running was tested during the dark (most active) period of the $12 \mathrm{~h}$ light/dark cycle between $9 \mathrm{am}$ and $20 \mathrm{pm}$ and at the same time of day.

\section{Systemic $\mathrm{MnCl}_{2}$ administration}

In Experiment 1, naive rats $(n=12)$ had access to the running wheel for $3 \mathrm{~h}$ per day for 6 consecutive days. On day 7, rats received a subcutaneous (s.c.) injection of $\mathrm{MnCl}_{2}\left(\mathrm{MnCl}_{2} \cdot\left(\mathrm{H}_{2} \mathrm{O}\right) 2\right.$, Merck 
KGaA, Germany) solution in saline $(16 \mathrm{mg} / \mathrm{kg} / 10 \mathrm{ml}$ ) or equivalent volume of saline $(10 \mathrm{ml} / \mathrm{kg})$. The injection was made $3 \mathrm{~h}$ before the running activity test to minimize a possible negative effect of the acute injection procedure on the rat behavior. The rat post-injection activity was tested for six consecutive days. Then, the effects of higher doses of $\mathrm{MnCl}_{2}$ were tested. On day 13, saline-treated rats received injection of $\mathrm{MnCl}_{2}(32 \mathrm{mg} / \mathrm{kg} / 10 \mathrm{ml}$ or $80 \mathrm{mg} / \mathrm{kg} / 10 \mathrm{ml}$; $n=3$ for each dose); $\mathrm{MnCl}_{2}$-treated rats served as control and received the saline injection $(n=6)$. The rat post-injection activity was tested for another three days.

In Experiment 2, naive rats $(n=6)$ had access to the running wheel for $3 \mathrm{~h}$ per day for 6 consecutive days. On day 7 , rats received an intraperitoneal injection (i.p.) of either $\mathrm{MnCl}_{2}(80 \mathrm{mg} / \mathrm{kg} / 10 \mathrm{ml})$ or equivalent volume of saline $(10 \mathrm{ml} / \mathrm{kg}) 3 \mathrm{~h}$ before the activity test and the rat post-injection activity was tested. The second injection was made when both groups of rats showed similar running activity. Saline-treated rats received injection of $\mathrm{MnCl}_{2}(80 \mathrm{mg} / \mathrm{kg} / 10 \mathrm{ml})$ and $\mathrm{MnCl}_{2}$-treated rats received the saline injection. The rat post-injection activity was further tested daily for one week.

In Experiment 3, $\mathrm{MnCl}_{2}$ was administered using osmotic pumps (Alzet, Durect Corporation, Cupertino, CA, USA). The pumps were implanted (i.p.) under general anesthesia using aseptic techniques. The 7-day pumps (total volume of $200 \mu \mathrm{l}$ and constant flow rate of $1 \mu \mathrm{l} / \mathrm{h}$ ) were loaded with $\mathrm{MnCl}_{2}(80 \mathrm{mg} / \mathrm{kg} / 200 \mu \mathrm{l})$ or saline. Rats were anesthetized with isoflurane (4.0\% induction, $2.0 \%$ maintenance). The abdomen skin and muscles were cut and the pump was quickly introduced into intraperitoneal space; the abdomen muscles and skin were then sutured. At the end of the surgery, animals received analgesic (Fynadine ${ }^{\circledR}$ Essex, München, Germany; $0.25 \mathrm{mg} /$ kg; s.c.) and antibiotic (Baytril ${ }^{\circledR}$, Bayer, Leverkusen, Germany; $5 \mathrm{mg} /$ $\mathrm{kg}$; s.c.) medication and given $24 \mathrm{~h}$ post-surgery recovery. The next day rats were given access to the running wheels for $3 \mathrm{~h}$ per day for 6 consecutive days.

In addition to the running activity, the rats' weight and/or food and water intake were monitored daily throughout the testing period in all experiments.

\section{MRI data collection}

Based on the results of behavioral studies, the functional brain imaging was performed under the experimental conditions that produced minimal or no toxic effects of $\mathrm{MnCl}_{2}$. The first experimental group $(n=6)$ was subjected to the procedures described in Experiment 1 , except the running time was extended to $12 \mathrm{~h}$ per day for 6 consecutive days. On day 7, prior to the running test, rats were given a single injection of $\mathrm{MnCl}_{2}$ ( $16 \mathrm{mg} / \mathrm{kg}$, s.c.) and then scanned in the magnet. The second group of rats $(n=6)$ was subjected to the procedures described in Experiment 3, but with $12 \mathrm{~h}$ per day access to the running wheels for 6 days and then MRI scanning was performed. The control (sedentary) rats for both experimental conditions received the equivalent amount of $\mathrm{MnCl}_{2}$, but were kept in their home cages for the entire duration of the experiment.

For the MRI experiments, the animals were anesthetized with 1.5$2 \%$ isoflurane and placed in a modified saddle coil integrated within a stereotaxic animal holder (RAPID Biomedical, Rimpar, Germany). The head holder was adapted with movable bite and ear bars and positioned fixed on a magnet chair. This allowed precise positioning of the animal with respect to the coil and the magnet and avoiding movement artifacts. Body temperature, heart rate, $\mathrm{CO}_{2}$ and $\mathrm{SpO}_{2}$ were monitored throughout the scanning session. Each rat was subjected to a single scan session after the behavioral testing was completed.

A separate group of rats $(n=4)$ was used for characterization of the time course of manganese accumulation in different brain regions following a single $\mathrm{MnCl}_{2}$ injection (16 $\mathrm{mg} / \mathrm{kg}$, s.c.) or 7-day osmotic pump ( $11.4 \mathrm{mg} / \mathrm{kg} / 24$ h, i.p.). These rats were not subjected to any behavioral manipulations and scanned at multiple time points.
Experiments were carried out in a vertical 7T (300 MHz)/60-cm diameter bore magnet (Bruker BioSpin, Ettlingen, Germany). It is equipped with a gradient insert of $38-\mathrm{cm}$ inner diameter (Siemens AC44; Siemens Medical Solutions AG, Erlangen, Germany). The gradient system is driven by a Siemens gradient power amplifier with peak voltage of $700 \mathrm{~V}$ and current of 500A. A maximum of $40 \mathrm{mT} / \mathrm{m}$ gradient strength per channel can be achieved in less than $100 \mu \mathrm{s}$. The saddle coil, which was designed to generate a homogeneous field over the whole rat-brain, was used to transmit and receive. The MR system is controlled by a Bruker BioSpec console (ParaVision 3, 4 and 5 at different time periods) running under the Linux operating system. We used a modified driven equilibrium Fourier transform (MDEFT) method with MDEFTpreparation (Lee et al., 1995) to obtain T1-weighted anatomical images. The scan parameters were: $\mathrm{TR}=22.2 \mathrm{~ms}, \mathrm{TE}=4 \mathrm{~ms}, \mathrm{FA}=20^{\circ}$, $\mathrm{ID}=1000 \mathrm{~ms}$ and four segments. The inversion delay (ID) of the MDEFT preparation (responsible for the $\mathrm{T} 1$ contrast) was optimized in vivo for the contrast to noise ratio (CNR) of the thalamus after $\mathrm{Mn}^{2+}$ accumulation after local injection in the motor cortex (Canals et al., 2008). For terminal fields with lower accumulation of the ion, this ID is an appropriate compromise between scanning time and CNR. The geometric parameters of the 3D scans were matrix $192 \times 192 \times 80$, FOV $=48 \times 48 \times 40 \mathrm{~mm}$ and voxel size $0.25 \times 0.25 \times 0.5 \mathrm{~mm}$.

\section{Data analysis}

The behavioral data were analyzed using various designs of analysis of variance (ANOVA and MANOVA). When the assumption of sphericity was violated for ANOVA analyses, the degrees of freedom were adjusted using a Greenhouse-Geisser correction factor. The MRI images copped to the brain volume were analyzed with custom-developed Matlab functions (v7.5.0, MathWorks). The image cropping parameters were defined manually using brain landmarks (bifurcation of the Azygos anterior cerebral and the medial orbitofrontal arteries). An automated realignment procedure of SPM (statistical parametric mapping, www. fil.ion.ucl.ac.uk) was applied to co-register all scans. MRI images were then realigned to the stereotaxic rat brain template corresponding to the digitized rat anatomical atlas (Schwarz et al., 2006). This procedure resulted in automatic segmentation of up to 400 brain structures.

For statistical analysis, the image intensity was normalized to reference signal intensity. Due to likelihood of differential $\mathrm{Mn}^{2+}$ accumulation within both brain and muscle tissue in runners and sedentary rats, for the normalization of MR images we chose a tissue region around the nasal cavity, which lays in close proximity to the brain olfactory bulbs and showed no change in image intensity over time. Moreover, the intensity of this reference region should not be affected by manganese concentration due to running. Statistical maps were generated by implementing a Student's $t$-test (unpaired) at each voxel comparing two groups of rats (runners vs. sedentary). The significant voxels represent the pattern of runninginduced T1-weighted MRI signal enhancement due to increased $\mathrm{Mn}^{2+}$ accumulation in activated brain regions in the runners compared to the sedentary controls. The arbitrary significance threshold was set to $p<0.01$ (uncorrected for multiple comparisons) for individual voxels, and a minimum cluster size of 3 contiguous voxels constituting at least $3 \%$ of the total number of voxels for a given region of interest (ROI). The same data were also tested for lower or higher $p$-values. Several brain regions including amygdala and entorhinal cortex were excluded from ROI analysis due to image artifacts produced by ear canals.

\section{Results}

Behavioral effects of a single systemic injection of $\mathrm{MnCl}_{2}$

The voluntary running activity in intact rats was progressively increasing over 6 days of testing from $131.1 \pm 11.4$ to $301.2 \pm 42.7$ 
(mean $\pm \mathrm{SE}$ ) meters per hour as revealed by repeated measures ANOVA $\left(F_{2,34.5}=13.1, p<0.001\right.$; Supplementary Fig. 1$)$. The running activity did not depend on a particular time of day when the 3$\mathrm{h}$ test was performed $\left(F_{3.7,27.6}=1.32\right.$, ns for test $\times$ time interaction). Due to substantial individual variability in voluntary running activity (e.g. min/max: 147.6/792.2 $\mathrm{m}$ per hour on day 6), rats were distributed between experimental groups such that there was no between groups difference in running activity on the last pretreatment day 6 (Fig. 1A). A single injection of a small dose of $\mathrm{MnCl}_{2}$ (16 mg/kg, s.c.) on day 7 resulted in decreased wheelrunning activity compared to both pre-injection level and salineinjected control rats (Fig. 1A). Although the difference between two experimental groups did not reach statistical significance $(p=0.08)$, a lower running activity in $\mathrm{MnCl}_{2}$-treated rats (67-89\% of the control group level) was observed for 6 successive days of testing (Fig. 1A).

The effects were more dramatic when the higher doses of $\mathrm{MnCl}_{2}$ were tested. Six days after the first injection, the rats were redistributed in 3 experimental groups such that they showed comparable running activity before the second injection (Fig. 1B). $\mathrm{MnCl}_{2}$-treated rats $(n=6)$ received saline injection and served now as a control group, while saline-treated rats received either $32(n=3)$ or $80 \mathrm{mg} / \mathrm{kg}(n=3)$ of $\mathrm{MnCl}_{2}$. Multivariate Pillai's
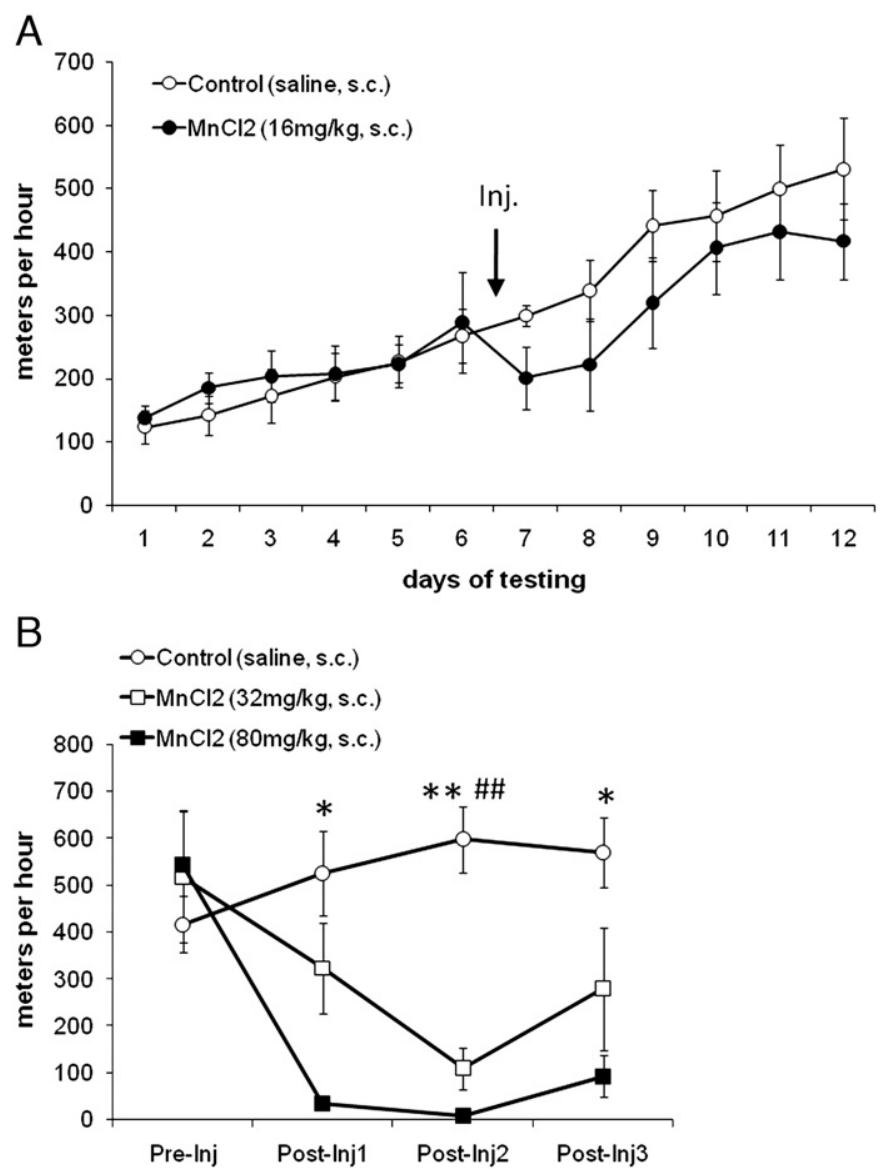

Fig. 1. Manganese-induced effects on rat voluntary wheel running. (A) Effects of a low dose of $\mathrm{MnCl}_{2}(16 \mathrm{mg} / \mathrm{kg}$, s.c.). Lines represent an average running speed (meters per hour) over 12 days of testing before (days 1-6) and after (days 7-12) a single s.c. injection $\mathrm{MnCl}_{2}$ (16 mg/ $\mathrm{kg}$; filled circles) or equivalent volume of saline (10 ml/ kg; open circles). (B) Wheel running after a second injection of either $32 \mathrm{mg} / \mathrm{kg}$ of $\mathrm{MnCl}_{2}$ (open squares), $80 \mathrm{mg} / \mathrm{kg}$ of $\mathrm{MnCl}_{2}$ (filled squares) or saline (open circles). Note a dose-dependent and long-lasting manganese-induced decrease of rat running activity after a single systemic injection of $\mathrm{MnCl}_{2}$. Pre-Inj: $3 \mathrm{~h}$ test on a day preceding an injection; Post-Inj1: 3-6 h post-injection; Post-Inj2: 27-30 h post-injection; Post-Inj3: 51-54 h post-injection. ${ }^{*} p<0.05$; ${ }^{* *} p<0.01$ for $80 \mathrm{mg} / \mathrm{kg}$; \#\#p $<0.01$ for $32 \mathrm{mg} / \mathrm{kg}$ of $\mathrm{MnCl}_{2}$ compared to control (saline-injected) group. Error bars represent $\pm 1 \mathrm{SEM}$.
Trace test revealed a significant effect of the day of testing and day $x$ group interaction $\left(F_{3,7}=7.67, p=0.013\right.$ and $F_{6,16}=6.49$, $p=0.001$, respectively). Between-subject comparison showed a significant group effect $\left(F_{2.9}=7.75, p=0.011\right)$. Subsequent withingroup repeated measures ANOVA indicated that the significant day effect was present exclusively after the injection of $\mathrm{MnCl}_{2}$ $\left(F_{3,6}=12.78, p<0.01\right.$ and $F_{3,6}=15.05, p<0.01$, for 32 and $80 \mathrm{mg} /$ $\mathrm{kg}$, respectively), while performance of the saline-injected rats was stable $\left(F_{3,15}=1.95\right.$, ns). Post hoc Scheffe comparisons confirmed that there were no between-group differences on the pre-injection day; $80 \mathrm{mg} / \mathrm{kg}$ produced the strongest effect on rat voluntary running as the significant effect was present at all three time points tested (Fig. 1B). The running activity after $32 \mathrm{mg} / \mathrm{kg}$ was significantly decreased 24 h post-injection, but has not completely recovered for at least 3 consecutive days (Fig. 1B). Fig. 2A summarizes the results for all three tested doses of $\mathrm{MnCl}_{2}$ illustrating a dose-dependent, sustained reduction of the rat voluntary running after a single s.c. injection of $\mathrm{MnCl}_{2}$.

The manganese-induced decrease of running activity was accompanied by decrease in food intake (Fig. 2B) and as a consequence by decrease of body weight, particularly after injection of the highest dose (Fig. 2C). There were no consistent changes in water intake. In addition, signs of skin irritation around the injected area were observed, but only after the injection of the highest dose of $\mathrm{MnCl}_{2}$.

To eliminate possible effects of the administration route, a separate group of rats $(n=6)$ was tested using a similar experimental design as in Experiment 1, except of the route of systemic $\mathrm{MnCl}_{2}$ administration (i.p.). Rats were first given free access to the running wheel $3 \mathrm{~h}$ per day for six consecutive days and on day 7 were injected either with $80 \mathrm{mg} / \mathrm{kg}$ of $\mathrm{MnCl}_{2}$ ( $n=3$, i.p.) or equivalent volume of saline $(n=3$, i. p.) $3 \mathrm{~h}$ prior to the wheel running test. The rat running activity was monitored $24 \mathrm{~h}$ and 7 days post-injection to ensure complete recovery of the activity level prior to the second injection. Then, rats received a second injection in a counter-balanced manner: saline-treated rats received $80 \mathrm{mg} / \mathrm{kg}$ of $\mathrm{MnCl}_{2}$ and manganese-treated rats received control saline injection. A single i.p. injection of $\mathrm{MnCl}_{2}$ resulted in a dramatic (averaged at $15 \%$ of the control level) decrease of the rat voluntary running activity already $3 \mathrm{~h}$ after injection (Fig. $3 \mathrm{~A}$ ). The activity was significantly reduced 24 h later (on average, 35\% of control level) and slowly recovered by the post-injection day 7 (Fig. $3 \mathrm{~A}$ ). There was also a significant drop in body weight $24 \mathrm{~h}$ postinjection, most likely related to a decreased food intake (Fig. 3B).

Thus, acute systemic injections of $\mathrm{MnCl}_{2}$ independently of the route of administration severely affected the animal's 'well-being' state as reflected in voluntary wheel running, food intake and body weight. The manganese-induced effects were dose-dependent, were present already $3 \mathrm{~h}$ post-injection and reached their maximum 24 $\mathrm{h}$ post-injection. The effects of manganese were reversible, but showed a rather slow dose-dependent recovery lasting 3 to 7 days.

\section{Effects of systemic administration of $\mathrm{MnCl}_{2}$ via chronically implanted osmotic pumps}

In Experiment 3, rats were first implanted with osmotic pumps loaded either with $200 \mu \mathrm{l}$ of saline $(n=6)$, or $\mathrm{MnCl}_{2}$ dissolved in saline such that the total amount of $\mathrm{MnCl}_{2}$ in a pump was equivalent to $80 \mathrm{mg} / \mathrm{kg}(\mathrm{n}=9)$. After $24 \mathrm{~h}$ post-surgery recovery, the rats were given access to the running wheels for $3 \mathrm{~h}$ per day for six consecutive days. The running activity of rats implanted with pumps was compared to the activity of naive rats $(n=18)$ used in the Experiments 1 and 2 (data before injection; days 1-6). A two-way ANOVA with day of testing as a repeated factor and type of treatment as between group factor revealed a significant day effect $\left(F_{1.99,59.4}=\right.$ 29.70, $p<0.001$ ) indicating a progressive increase of the running activity over days (Fig. 4). Further statistical tests showed that neither a pump implantation procedure (group with saline-loaded pumps) 

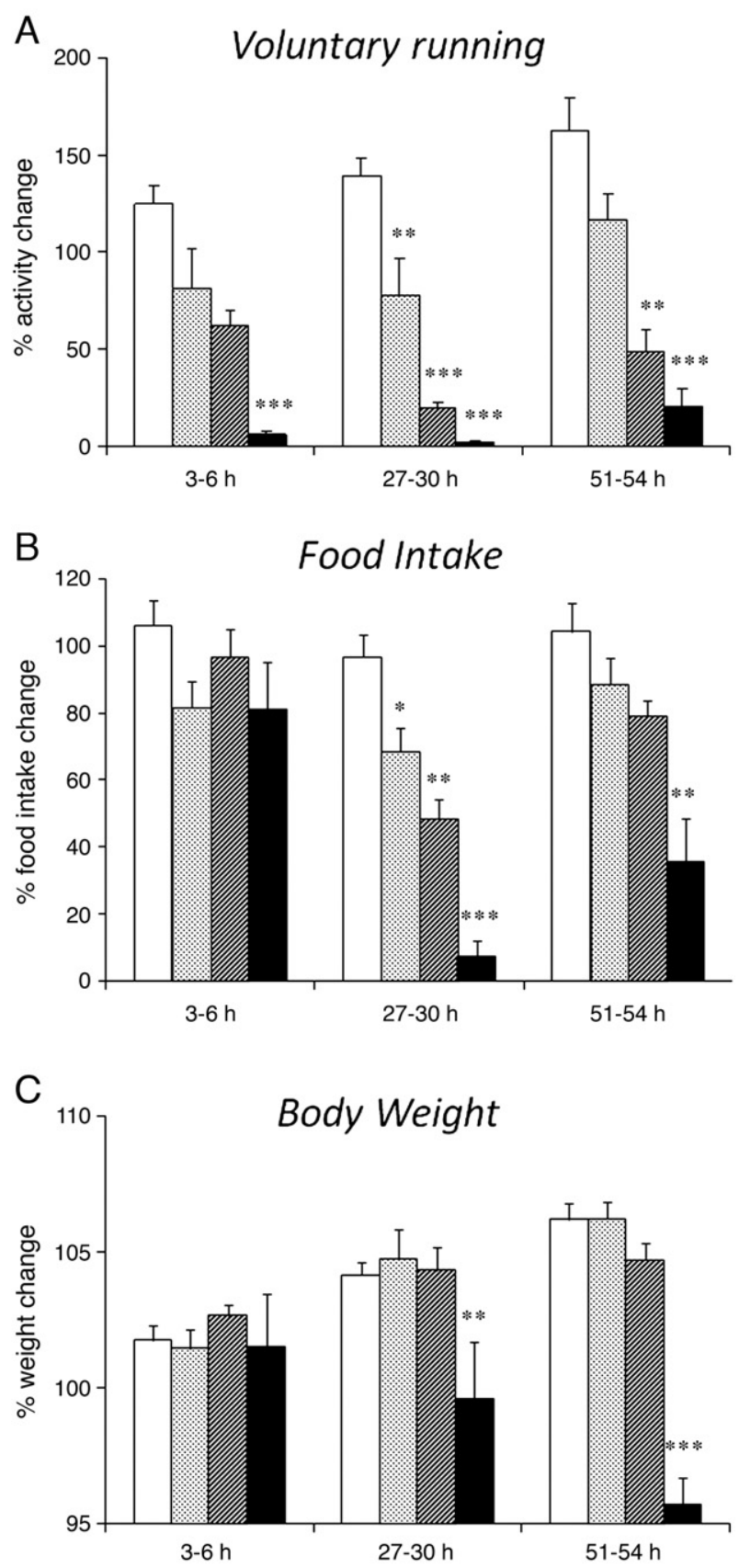

Fig. 2. Effects of different doses of $\mathrm{MnCl}_{2}$ on rat voluntary wheel running (A), body weight (B) and food intake (C). Bars represent a group mean percent change compared to a pre-injection level at different post-injection times. Error bars represent \pm 1 SEM. Saline injection, open bars; $16 \mathrm{mg} / \mathrm{kg}$, dotted bars; $32 \mathrm{mg} / \mathrm{kg}$, striped bars; $80 \mathrm{mg} / \mathrm{kg}$, black bars. Note a dose-dependent and prolonged effects on all parameters tested. $* p<0.05 ; * * p<0.01$ and $* * * p<0.001$ compared to a corresponding parameter of the control (saline-injected) group.

nor manganese administration via osmotic pumps affected the rat wheel running as there was no significant day $\times$ treatment interaction $\left(F_{3.96,59.4}=1.12\right.$, ns $)$ or overall between group differences $\left(F_{2,30}=1.03, \mathrm{~ns}\right)$.

The food and water intake was also not affected by either of the experimental manipulations as revealed by a one-way ANOVA $\left(F_{2.23}=2.64\right.$, ns and $F_{2.23}=0.90$, for food and water intake, respectively). Despite the equal food and water intake, the weight gain over 6 days of testing was different between groups $\left(F_{2.23}=10.67\right.$, $p=0.001$ ). Post hoc comparisons confirmed that overall weight gain was slightly higher in the intact animals relative to the rats with
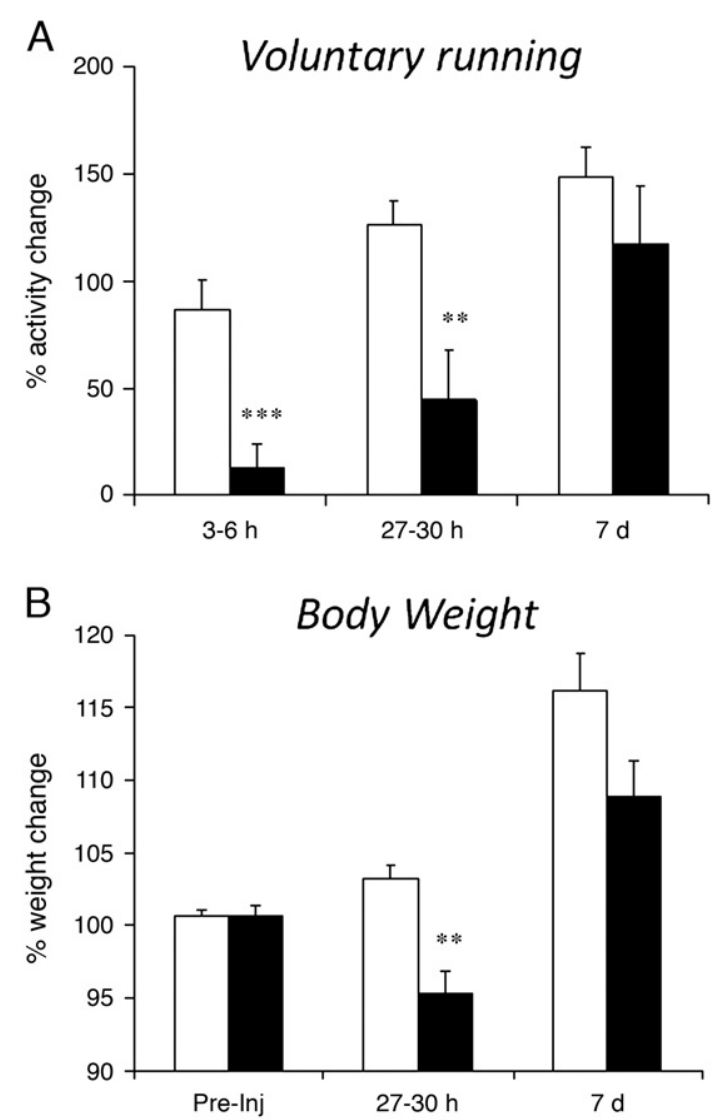

Fig. 3. Effects of a single i.p. injection of different doses of $\mathrm{MnCl}_{2}$ on rat voluntary wheel running (A) and body weight (B). Bars represent a group mean percent change compared to a pre-injection level after saline (open bars) and $80 \mathrm{mg} / \mathrm{kg}$ of $\mathrm{MnCl}_{2}$ (black bars) at different post-injection times. Error bars represent \pm 1 SEM. Note the dosedependent and prolonged effects, which are comparable with an s.c. injection (Figs. 1 and 2). ${ }^{* *} p<0.01$ and $* * * p<0.001$ compared to a corresponding parameter in the control (saline-injected) group.

implanted pumps. Importantly, there was no difference between rats with $\mathrm{NaCl}$ - or $\mathrm{MnCl}_{2}$-loaded pumps (Supplementary Fig.2); the latter indicates that a lesser weight gain was not due to a manganese exposure, but possibly due to a surgical procedure. In addition, considerable between-subject variability in other parameters, such as running preference or energy metabolism likely contributes into this result. For example, a significant negative correlation was found

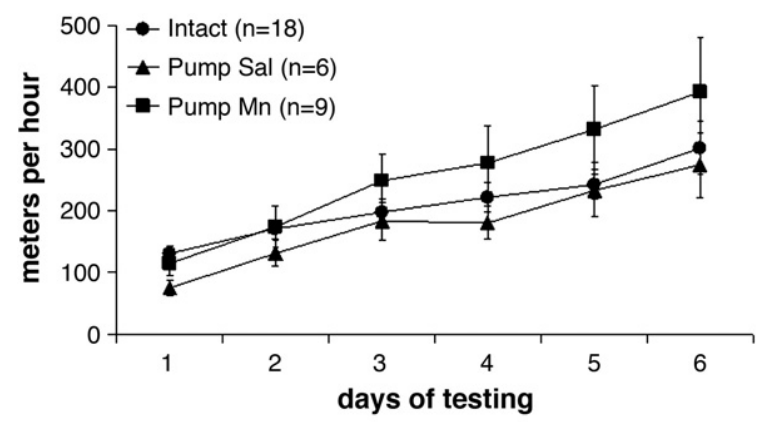

Fig. 4. Effects of chronically implanted osmotic pumps on the rat voluntary running. The amount of running progressively increased over six consecutive days of testing in all experimental groups. Daily mean running speed ( \pm 1 SEM) for each experimental group is shown. Note that neither the pump implantation procedure (saline-loaded pumps; line with triangles), nor $\mathrm{MnCl}_{2}$ administration (80 $\mathrm{mg} / \mathrm{kg} / 7$ days, release rate $1 \mu \mathrm{l} / \mathrm{h}$; line with squares) did affect the rat wheel running compared to intact group (line with circles). 


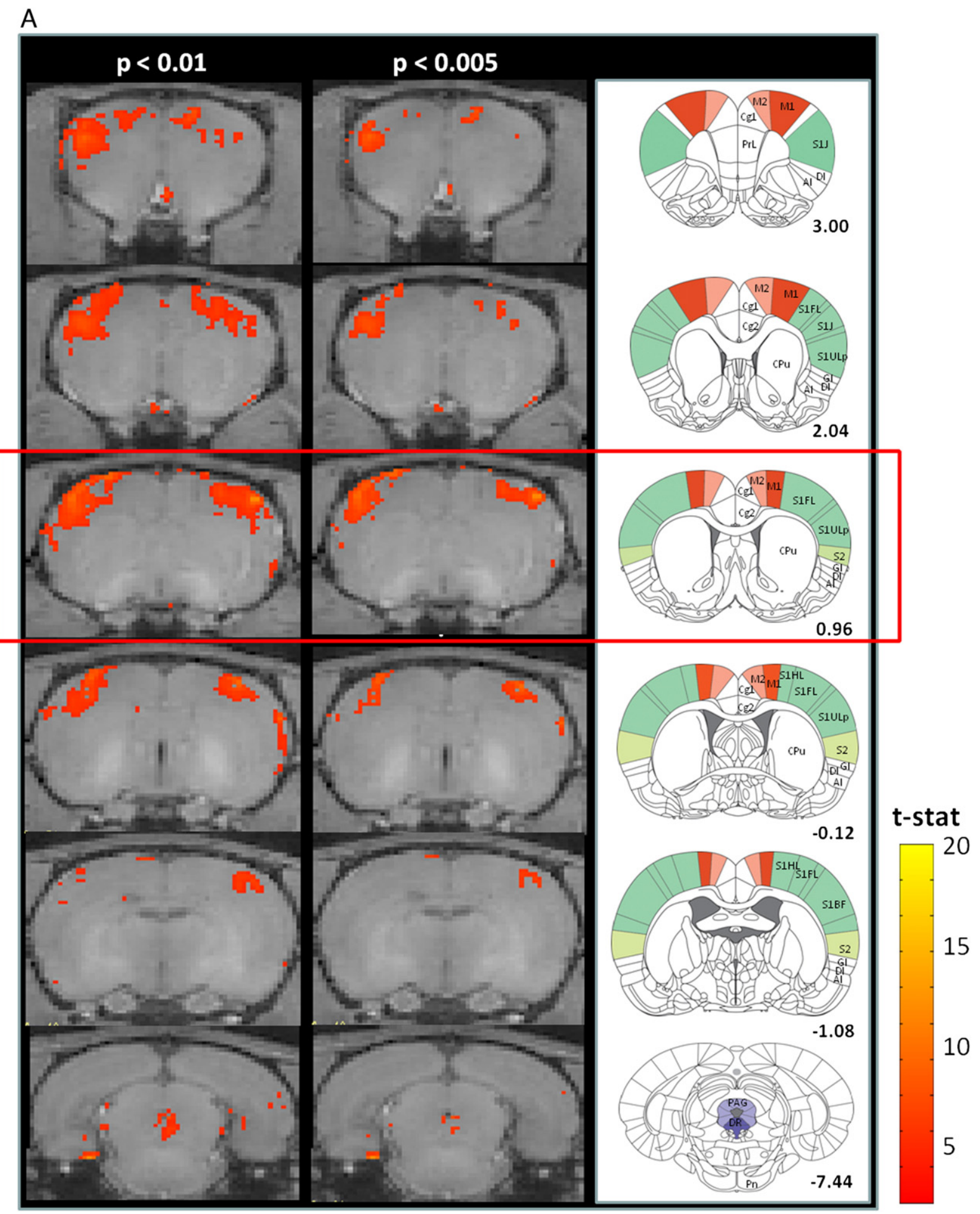

Fig. 5. (A) Regions of brain activation related to movements in the running-wheel as revealed by increased intensity of T1-weighted images due to $\mathrm{Mn}^{2+}$ accumulation in runners $(n=6)$ compared to sedentary $(n=6)$ rats. Left and middle columns: color-coded $t$-test maps superimposed on the representative coronal sections. Right column: corresponding sections from the rat atlas of Paxinos and Watson (2005) with highlighted primary and secondary motor (red) and sensory (green) cortices; numbers below the sections indicate their position relative to bregma in millimeters. Note the strong and selective activation of the sensory- and motor-related cortical areas, as well as of certain brain regions nuclei (e.g. DR, dorsal raphe; PAG, periaqueductal grey, bottom raw). Cg1, cingulate cortex, area 1; Cg2, cingulate cortex, area 2; M1, primary motor cortex; M2, secondary motor cortex; PrL, prelimbic cortex; S1J, primary somatosensory cortex, jaw region; S1FL, primary somatosensory cortex, forelimb region; S1HL, primary somatosensory cortex, hind limb region; S1Ulp, primary somatosensory cortex, upper lip region; S1BF, primary somatosensory cortex, barrel field; S2, secondary somatosensory cortex; GI, granular insular cortex; DI, dysgranular insular cortex; AI, agranular insular cortex; CPu, caudate putamen; Pn, pons. (B) Spatial correspondence between the statistical map (left panel), automatically detected regions of interest (two middle panels) and the structures outlines in the rat brain atlas (right panel). Note that a large fraction of significant voxels corresponds to the somatosensory cortex. The coronal plane highlighted by a red frame on panel A is shown. 
B

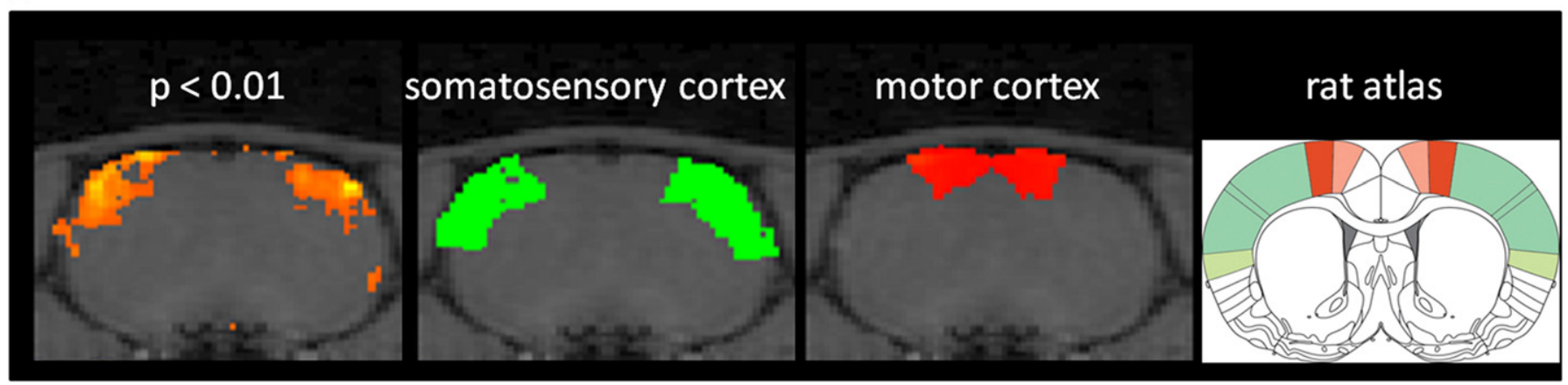

Fig. 5 (continued).

between the amount of running activity and weight gain $(r=-0.39$, $p<0.05$ ) regardless of a particular experimental condition.

The results of this experiment clearly demonstrate the advantage of systemic administration of $\mathrm{MnCl}_{2}$ via osmotic pumps, which provide a long-lasting, continuous and slow release of $\mathrm{Mn}^{2+}$ into intraperitoneal space ( $1 \mu \mathrm{l} / \mathrm{h}$ for 7 days). Such release rate likely is readily managed by homeostatic mechanisms, does not produce toxic effects, while allows reaching relatively high cumulative dose.

\section{Functional mapping of brain activity in behaving rats using MEMRI}

Based on the results of the behavioral study described above, for functional mapping experiments with MEMRI, we used a single injection of $\mathrm{MnCl}_{2}$ (16 mg/ $\mathrm{kg}$, s.c.) or $\mathrm{MnCl}_{2}$-loaded osmotic pumps providing a cumulative concentration of $80 \mathrm{mg} / \mathrm{kg}$ over 7 days (Supplementary Fig.3). Both modes of systemic administration of $\mathrm{MnCl}_{2}$ produced minimal or no toxic effects, respectively, on the rat wheel running, food and water intake or general well-being (Figs. 1 and 2). To maximize the activity-related accumulation of $\mathrm{Mn}^{2+}$ in the brain, the wheel access time was extended to $12 \mathrm{~h}$ per day.

The supplementary MRI measurements of the time course of $\mathrm{Mn}^{2+}$ accumulation in the brain were performed on a separate group of rats $(n=4)$ and illustrated on the Supplementary Fig. 4. Two rats per each condition were scanned at different time points before and after $\mathrm{MnCl}_{2}$ administration. Acute administration of relatively low dose of $\mathrm{MnCl}_{2}$ (16 mg/kg, s.c.) resulted in a substantial enhancement of MR image signal intensity reaching maximum 24 h post-injection. Signal intensity was the highest in brain areas lacking brain-blood barrier (BBB), such as the pituitary gland (Pit), the intensity of which doubled compared to the pre-injection level (Supplementary Figs. 4A, B). SNR across different brain regions varied within a range $22-29 \%$ increase, compared to a pre-injection level (Supplementary Fig. 4B). Continuous application of a very low dose of $\mathrm{MnCl}_{2}(11.4 \mathrm{mg} / \mathrm{kg} / 24 \mathrm{~h})$ via $\mathrm{MnCl}_{2}$-loaded osmotic pumps resulted in a gradual increase of MR image signal intensity reaching a plateau after 3 days (Supplementary Fig. 4C). SNR enhancement was 13-30\% across different brain regions, but $\sim 200 \%$ for Pit. Thus, both administration methods provided MRIdetectable and comparable amounts of $\mathrm{Mn}^{2+}$ ions in the rat brain.

In the case of single s.c. injection, one group of rats (runners, $n=6$ ) was first given access to the running wheels for six days, while the control rats (sedentary, $n=7$ ) were kept in their home cages. On day 7, all rats (runners and sedentary) were injected with $16 \mathrm{mg} / \mathrm{kg}$ of $\mathrm{MnCl}_{2}$ (Supplementary Fig. 3A). After injection, runners were given another 12-h access to the wheels, while the control sedentary rats were returned to their home cages. All rats were scanned $24 \mathrm{~h}$ postinjection under isoflurane anesthesia. The injection of $\mathrm{MnCl}_{2}$ resulted in a substantial decrease of locomotor activity as was reflected by the total distance traveled $(1.52 \pm 0.21$ and $0.66 \pm 0.19 \mathrm{~km}$ on the preand post-injection days, respectively; Supplementary Fig. 3A). In contrast to the results of the 3 -h wheel test (Experiment 1 ) when the decrease of running did not reach statistical significance, the observed effect was highly significant when the test time was extended to 12 $\mathrm{h}$ (paired $t$-test: $t_{5}=4.85, p<0.01$ for pre- and post-injection days comparison).

Analysis of MRI images showed that SNR of the pituitary gland (Pit) did not differ significantly between runners and sedentary rats $(19.56 \pm 0.93$ and $20.98 \pm 1.88$, respectively; one-way ANOVA: $F_{1,12}=0.42$, ns) indicating equal availability of $\mathrm{Mn}^{2+}$ in the blood in both experimental groups. Statistical comparison of MRI images from runners and sedentary rats failed to detect any difference in distribution of image signal intensity across the entire brain volume even when the significance level was set to $p<0.05$ (voxel-by-voxel comparison; unpaired Student's t-test).

In the second experimental condition, all rats $(n=12)$ were first implanted with osmotic pumps and divided in two groups (runners and sedentary). Six rats were given access to the running wheels for 6 days, while the control six rats were kept in their home cages. The total distance traveled by the group of runners before the scan was $6.98 \pm 0.79 \mathrm{~km}$. On day 7 , all rats were scanned in the magnet (Supplementary Fig. 3B). The coronal sections of raw MDEFT images of all rats contributed to between-group statistical analyses are presented on the Supplementary Fig. 5A.

SNR in Pit after 7 days of manganese application did not differ between runners and sedentary rats $(23.47 \pm 1.35$ and $20.98 \pm 1.17$, respectively; one-way ANOVA: $F_{1,11}=1.92$, ns). Furthermore, it was comparable with such values $24 \mathrm{~h}$ after a single s.c. injection (Supplementary Fig. 4C). Fig. 5A illustrates the brain regions with statistically significant elevated accumulation of $\mathrm{Mn}^{2+}$ in pumpimplanted rats exposed to the running wheels $12 \mathrm{~h}$ per day for 6 days compared to the control (sedentary) rats with matching exposure to $\mathrm{MnCl}_{2}$. Table 1 summarizes all brain regions (out of 379 automatically segmented ROIs) that contained at least 3 contiguous significant voxels constituting at least $3 \%$ ROI (see Methods for details). As listed in the Table 1, the strongest activation was observed in the primary motor (M1) and somatosensory (S1) cortices (23\% and 28\% of ROI, respectively, with voxel-based $t$-test significance level, $p<0.01$; Fig. $5 \mathrm{~B})$. The corresponding secondary cortices (M2 and S2) were also activated, however, to a lesser extent (6-7\% ROI). The activation of these cortical regions was predictable and in agreement with other functional mapping studies using different brain imaging methods (Holschneider et al., 2003; Rhodes et al., 2003). Strikingly, activation was also observed in a number of brain stem structures including serotonergic nucleus dorsal raphe (36\% ROI), periaqueductal grey ( $24 \%$ ROI) and pontine nuclei (20\% ROI), which constitute a "mesencephalic locomotor region" (MLR). A constellation of brain stem nuclei in MLR has been hypothesized to directly activate corticospinal cells to initiate and control different forms of locomotion (Jordan, 1998). In addition, a substantial activation was detected in 
Table 1

Brain regions containing statistically significant voxels of functional brain activation in runners compared to sedentary rats.

\begin{tabular}{|c|c|c|c|c|c|c|}
\hline & & $\begin{array}{l}\text { Number of voxels per } \\
\text { individual ROI }\end{array}$ & $\begin{array}{l}\text { Number of significant } \\
\text { voxels; } p<0.01\end{array}$ & $\%$ ROI; $p<0.01$ & $\begin{array}{l}\text { Number of significant } \\
\text { voxels; } p<0.005\end{array}$ & $\begin{array}{l}\% \text { ROI; } \\
p<0.005\end{array}$ \\
\hline Primary motor cortex & M1 & 3193 & 734 & 23 & 317 & 10 \\
\hline Secondary motor cortex & M2 & 1970 & 147 & 7 & 43 & 2 \\
\hline Primary somatosensory cortex & S1 & 7501 & 2078 & 28 & 1125 & 15 \\
\hline Secondary somatosensory cortex & S2 & 1368 & 88 & 6 & 25 & 2 \\
\hline Dorsal raphe nucleus & DRD & 14 & 5 & 36 & 2 & 14 \\
\hline Periaqueductal grey & PAG & 276 & 67 & 24 & 15 & 5 \\
\hline Pons & Pn & 41 & 8 & 20 & 1 & 2 \\
\hline Insular cortex & Ins & 2101 & 281 & 13 & 108 & 5 \\
\hline Olfactory bulb & $\mathrm{OB}$ & 704 & 71 & 10 & 38 & 5 \\
\hline Subiculum & Sub & 1237 & 84 & 7 & 28 & 2 \\
\hline Hippocampus, ventral part & $\mathrm{HC}$ & 1742 & 97 & 6 & 34 & 2 \\
\hline Piriform cortex & Pir & 4680 & 232 & 5 & 99 & 2 \\
\hline Sensory root of the trigeminal nerve & s5 & 190 & 6 & 3 & 3 & 2 \\
\hline Auditory Cortex & $\mathrm{Au}$ & 1618 & 49 & 3 & 9 & 1 \\
\hline Substantia nigra, reticular part & SNR & 215 & 5 & 2 & 2 & 1 \\
\hline Cingulate cortex & $\operatorname{Cg} 1$ & 660 & 29 & 4 & 7 & 1 \\
\hline Temporal association cortex & TeA & 665 & 17 & 3 & 3 & 0 \\
\hline Prelimbic cortex & PrL & 560 & 19 & 3 & 1 & 0 \\
\hline Cerebral peduncle, basal part & $C p$ & 275 & 9 & 3 & 1 & 0 \\
\hline
\end{tabular}

insular cortex, subiculum and ventral hippocampus, while minimal or no activation was noted in other brain regions (Table 1 ). The pattern of activated regions was extremely consistent when a lower level of significance $(p<0.005)$ was applied, except for temporal association cortex, prelimbic cortex and cerebral peduncle (Fig. 5A).

\section{Discussion}

The results of the present study convincingly demonstrate that continuous and slow administration of $\mathrm{MnCl}_{2}$ over prolonged period is advantageous for longitudinal behavioral studies compared to a single systemic injection of the same dose. The method described here allows avoiding toxic effects of manganese, while the latter reaches MRI-detectable cumulative amounts in the brain. Chronically implanted osmotic pumps are perfectly suited for such purpose. They provide a nicely controlled continuous and slow release of $\mathrm{Mn}^{2+}$ over multiple days. In contrast to a single injection, such slow release rate of manganese likely is readily managed by homeostatic mechanisms and therefore does not produce acute toxic effects. Using this administration method, we have also demonstrated the possibility of functional brain mapping in unrestrained and naturally behaving rats.

The study by Lin and Koretsky (1997) paved the way for functional brain imaging using MEMRI. The activity-induced MEMRI (AIM-MRI) takes advantage of the slow efflux of $\mathrm{Mn}^{2+}$ from the brain, so that the pattern of manganese accumulation is retained for long time, enabling MRI to be performed after the behavioral testing. In combination with the basic principles of MEMRI, i.e. the paramagnetic nature of manganese, and its neural activity-dependent increases within the cells, AIM-MRI has been now used for different applications including functional mapping of sensory pathways in awake and unrestrained animals (Bissig and Berkowitz, 2009; Chuang et al., 2009; Yu et al., 2005). In our study, we implanted rats with manganese-loaded osmotic pumps and gave the animals a free access to a running wheel for 6 days. Wheel running resulted in elevated accumulation of $\mathrm{Mn}^{2+}$ in the motor and somatosensory circuits including forebrain and mesencephalic structures (Fig. 5).

The pattern of activated brain regions was highly selective and in accordance with existing studies employing other brain imaging techniques like cerebral blood flow-related autoradiography, PET, or immunohistochemistry (Holschneider et al., 2003; Jordan, 1998; Nguyen et al., 2004; Rhodes et al., 2003). Yet, a possibility of some "false alarms" cannot be completely excluded and should be interpreted with caution, particularly in cases of significant activation detected in small brain nuclei. Some voxels constituting a particular ROI may in principle label a corresponding brain region as "active" because of partial-volume averaging, for example if there is significant tracer accumulation in the neighboring regions or in the locations of abrupt change in signal intensity. In addition, randomly distributed significant voxels within a given ROI may also be misleading if no clustering-methods are used or the number of voxels constituting a reliable activation-cluster is small. On the other hand, elevated activity in several brain regions (e.g. striatum, thalamic nuclei) known to be involved in motor and sensory processing was not detected in the present study. Several factors may account for this result. For instance, a sparse (less than 3 contiguous voxels), or proportionally small (less than $3 \%$ ROI) increase in a given ROI at a chosen significance level $(p<0.01)$ failed to satisfy our criteria for activation. Greater individual variability in activity of a given structure or insufficient $\mathrm{Mn}^{2+}$ accumulation may contribute to the lack of significant between-group differences. A larger group size ( $n>6$ rats) or longer exposure time may increase the statistical power. A "ceiling" effect of $\mathrm{Mn}^{2+}$ accumulation (e.g. in striatum) may also played a role. Finally, a spatial inhomogeneity of MR image intensity due to differential susceptibility to artifacts may also be considered.

There is a persistent notion in the literature that manganese accumulates in the brain predominantly in the basal ganglia, while little or no accumulation is typically observed in the neocortex (Dorman et al., 2006; Finkelstein et al., 2008; Kim, 2004; Newland et al., 1989; Normandin et al., 2004). According to a recent study, such differential distribution of manganese in the brain can be explained by preferential manganese transport via cerebrospinal fluid (CSF) and thus a higher manganese uptake in the brain structures adjacent to the ventricles (Bock et al., 2008a). Manganese-enhanced tissue contrast in cortical regions has been also reported in animals by several investigators, yet using much higher manganese concentrations than used in the present study (Bissig and Berkowitz, 2009; Bock et al., 2009; Silva et al., 2008). In the present study, a trans-synaptic manganese transport along the activated neural pathways likely contributed to the cortical labeling.

In our experiments, the manganese supply to the brain did not differ between the runners and sedentary rats as indicated by the manganese content in the pituitary gland, a structure lacking BBB and thus accumulating the highest amount of manganese. The latter provides further evidence that the reported differential manganese accumulation in the runners and sedentary rats is caused by difference in the functional load in a specific subset of brain structures. 
On the other hand, we cannot exclude the possibility that the increased accumulation of manganese in the functionally activated brain regions - at least to some extent - results from an accelerated direct transport of manganese from the blood stream across BBB of the cerebral capillaries via a non-specific metal transporters (Takeda, 2003). It has been shown that at high plasma concentrations transport across the choroid plexus is more prevalent, while at normal plasma concentrations the transport across cerebral capillaries dominates (Murphy et al., 1991; Rabin et al., 1993); the latter could be true in case of low doses of manganese. More experiments will be required to clarify the extent to which MEMRI is independent from neurovascular effects.

Notably, the manganese treatment via chronically implanted osmotic pumps ( $11.4 \mathrm{mg} / \mathrm{kg} / 24 \mathrm{~h}$ for 7 days) did not produce any detectable adverse effects expressed in voluntary running activity, food or water intake and body weight; all these parameters being quantitatively analyzed. In contrast, a single s.c. or i.p. application of $\mathrm{MnCl}_{2}$ in a dose range of $16-80 \mathrm{mg} / \mathrm{kg}$ resulted in abrupt and longlasting toxic effects. Specifically, a substantial decrease of voluntary running activity was detected already $3 \mathrm{~h}$ post-injection; food intake was reduced causing a significant weight loss $24 \mathrm{~h}$ post-injection. These behavioral indices of manganese-induced toxicity slowly recovered to the baseline level during 3 to 7 post-injection days. Obviously, such adverse behavioral manifestations are highly undesirable for the whole set of behavioral studies, which critically depend on the animal well-being and involve testing of such cognitive functions as perception, attention, learning and memory, etc.

\section{Manganese-induced motor dysfunction}

Manganese-induced motor disturbances have been reported by numerous toxicological studies. Manganese is a micronutrient essential for a diverse range of biological functions, but harmful to the central nervous system at excessive exposures. Various symptoms of manganese toxicity are routinely tested in animals (Burton and Guilarte, 2009; Calabresi et al., 2001; Gwiazda et al., 2007; Newland, 1999; Olanow et al., 1996; Shukakidze et al., 2003). In particular, the effect of manganese on motor function has been reliably reproduced in different animals and experimental paradigms; this effect is apparent across a wide range of doses, different routes of administration and chemical species of manganese (Calabresi et al., 2001; Dodd et al., 2005; Mohammad and Faris, 2006; Nam and Kim, 2008; Newland and Weiss, 1992; Normandin et al., 2004). Manganese treatment typically results in decreased motor activity or disturbances in motor coordination, although a manganese-induced hyperactivity has also been reported (Calabresi et al., 2001; Eriksson et al., 1987). The effects are usually reversible, dose-dependent and often remain long after the end of manganese administration.

Although the mechanisms underlying manganese neurotoxicity remain unclear, experimental evidence exists that manganese may affect dopaminergic and cholinergic neuromodulatory systems, which may lead to various cognitive and neurological disorders including motor dysfunction (Calabresi et al., 2001; Eriksson et al., 1987; Nam and Kim, 2008; Newland and Weiss, 1992; Olanow et al., 1996). Taking this into account, a successful application of MEMRI technique for longitudinal studies, particularly involving behaving animals, critically depends on the manganese administration regimen that does not or minimally compromise homeostatic capacity, while achieving MRI-detectable cumulative concentration of $\mathrm{Mn}^{2+}$ in the brain.

Contrary to numerous toxicological studies, there is a common consensus in the existing MEMRI literature that rodents do not develop serious behavioral abnormalities or neural deficits following manganese exposure (Bissig and Berkowitz, 2009; Bock et al., 2008a; Yu et al., 2005). Unfortunately, MRI studies do not necessarily include a formal behavioral test and an assessment of potential toxic effects of manganese is usually limited to a rather subjective general observation of animal behavior in the home cage. In our study, we used a voluntary wheel running test, which is a relatively easy, but quantitative method for measuring rodents' physical activity in response to chemical or environmental stimuli (Sherwin, 1998). In addition to testing toxic effects of $\mathrm{MnCl}_{2}$, we used this behavioral test to map functional brain activity with MEMRI in naturally behaving and actively moving animals.

\section{Voluntary running as an indicator of manganese-induced toxicity}

Voluntary wheel running is a wildly used behavioral model for rodents and other experimental animals (Sherwin, 1998). In fact, it is the most common behavior performed by captive animals and usually occurs spontaneously within a few minutes of access to the wheel. For many species, wheel running increases during the first few days (12-21 days for rats) and after this initial "learning" phase stabilizes and maintains at a baseline level in the absence of experimental manipulation (Premack and Schaeffer, 1963). In the rat, running almost exclusively occurs at night as many other appetitive behaviors (Eikelboom and Mills, 1988). It is generally agreed that wheel running is naturally rewarding and strongly depends on animal motivation to perform this behavior (Belke, 1997; Iversen, 1993; Yu et al., 2005). It has been demonstrated that the pattern of operant responding to gain access to a wheel was similar to those observed for conventionally accepted consummatory reinforces such as food and water (Belke, 1997). Due to a rather complex nature, wheel running is a highly plastic behavior and can be influenced by a variety of internal and external factors that justify its use in many applications. For example, the aversive effects (e.g. pain) might determine levels of voluntary wheel running (Sherwin, 1998). Finally, it is an extremely sensitive behavioral model. For example, it has been reported that changes in motor activity detected by running wheel were considerably greater compared to other testing apparatus (Sherwin, 1998).

In general, various forms of locomotor activity are used as an indicator of manganese toxicity (Calabresi et al., 2001; Gwiazda et al., 2007; Nam and Kim, 2008; Newland and Weiss, 1992). In the present study, we demonstrated a significant decrease in rat running activity after a single systemic injection of all tested doses of $\mathrm{MnCl}_{2}$ (16-80 $\left.\mathrm{mg} / \mathrm{kg}\right)$ using the voluntary wheel running model. Our result is in agreement with the existing literature as the manganese-induced motor deficits appear in both non-human primates and rodents at doses below $10 \mathrm{mg} / \mathrm{kg}$ (Gwiazda et al., 2007). In this respect, it is important to note that the sensitivity of behavioral tests in case of manganese toxicity overcomes that of other methods detecting biochemical or structural changes as a result of manganese exposure. Indeed, some evidence exists that motor effects of manganese neurotoxicity may be present before any functional, structural or degenerative changes in the manganese-affected brain regions, which typically appear at much higher doses (Gwiazda et al., 2007). In contrast, systemic administration of the equivalent cumulative amount of $\mathrm{MnCl}_{2}$ ( $80 \mathrm{mg} / \mathrm{kg} / 7$ days $)$ via osmotic pumps did not affect the rat motor activity during 6 consecutive days of testing. Thus, when evaluating manganese toxicity, it is important to consider both the sensitivity of the behavioral test and the administration regimen (dose, frequency and duration).

\section{Application of MEMRI for whole-brain mapping in behaving animals}

The ability of manganese to cross the BBB following systemic administration (Murphy et al., 1991; Rabin et al., 1993), enter excitable cells via voltage-gated $\mathrm{Ca}^{2+}$ channels (Drapeau and Nachshen, 1984; Lin and Koretsky, 1997; Narita et al., 1990; Silva et 
al., 2004) and accumulate in the activated brain regions gives the unique opportunity to use MEMRI for the whole-brain functional mapping. Exposure to subtoxic levels of manganese extends the application of this method to behaving animals. Furthermore, the use of a hypothesis-free image analysis allows detection of functional brain activation that would be difficult to predict a priori. This is particularly important for mapping the functional activity accompanying complex behaviors like learning when multiple brain areas are engaged in processing and the pattern of activation may vary at different times.

To validate this method for a longitudinal behavioral study, we chose a hypothesis-driven experimental design. The runningassociated brain activation pattern was predicted based on the results from the studies using other brain imaging techniques (Holschneider et al., 2003; Jordan, 1998; Nguyen et al., 2004; Rhodes et al., 2003). We compared the efficiency of acute s.c. injection of $\mathrm{MnCl}_{2}$, a common way of systemic administration in MEMRI studies, and via chronically implanted osmotic pumps, an alternative method of manganese delivery.

Based on our results (Experiment 1), the rat voluntary running activity was minimally affected by the lowest dose of $\mathrm{MnCl}_{2}$ (16 $\mathrm{mg}$ / $\mathrm{kg}$, s.c.). We, therefore, attempted to obtain the locomotion-related functional maps following an experimental design described by others for awake and unrestrained rats (Alvestad et al., 2007; Berkowitz et al., 2006; Bissig and Berkowitz, 2009; Yu et al., 2005). Rats were given access to the running wheels $12 \mathrm{~h} /$ day for six consecutive days and on day 7 they received a single s.c. injection of $\mathrm{MnCl}_{2}$. After the injection, rats were given an opportunity to run for 12 $\mathrm{h}$ and after then were scanned in the magnet. First, the extension of the wheel access time from $3 \mathrm{~h}$ /day to $12 \mathrm{~h}$ /day made our behavioral paradigm more sensitive as the manganese-induced decrease of running activity was now statistically significant even after application of the lowest dose of $\mathrm{MnCl}_{2}$. Analysis of MRI images did not reveal any significant differences in distribution of signal intensity between the running and sedentary conditions.

This result could be explained by numerous factors. First, the amount of $\mathrm{Mn}^{2+}$ in the brain provided by a relatively low dose of systemically administered $\mathrm{MnCl}_{2}$ (16 mg/ $\mathrm{kg}$ compared to $44-80 \mathrm{mg} / \mathrm{kg}$ used in other studies) could be insufficient for functional mapping. However, it has been reported that MRI-detectable brain tissue contrast can be reached after systemic application of a similar dose $\left(20 \mathrm{mg} / \mathrm{kg}\right.$, s.c.) of $\mathrm{MnCl}_{2}$ (Watanabe et al., 2004). Higher doses of $\mathrm{MnCl}_{2}$, as demonstrated in this study could not be applied due to severe and long-lasting impairment of the rat voluntary running activity and adverse effects on the rat general well-being (Figs. 1 and 2).

Second, a manganese-induced decrease of running activity that varied across animals from $5 \%$ to $63 \%$ of the pre-injection level was not sufficient for achieving significantly different image intensity in activated brain regions due to $\mathrm{Mn}^{2+}$ accumulation. The testing time of $12 \mathrm{~h}$ during the dark phase of $12 \mathrm{~h}$ light/dark illumination cycle corresponded to a period of maximal locomotor activity expressed by rats; locomotor activity during the light phase is essentially absent (Afonso and Eikelboom, 2003; Eikelboom and Mills, 1988). It is possible that an additional running activity over several post-injection days may result in successful mapping of motor circuitries using a low dose of $\mathrm{MnCl}_{2}$, given that manganese wash out from the brain is extremely slow (see Supplementary Fig. 4A). Although we cannot exclude a possibility of finding an appropriate protocol of manganese administration using a single or multiple systemic injections that does not affect animal behavior, we find the osmotic pump-administration protocol described in the present study clearly advantageous for longitudinal behavioral studies. Regardless of a particular mode, dose and regimen of manganese administration, the behavioral assessment in MEMRI experiments involving awake animals may be essential as it will allow avoiding the periods of acute adverse effects that may eventually affect the imaging results and their interpretation.
By now, there are several studies in which $\mathrm{Mn}^{2+}$ was given to animals while they were exposed to various sensory stimuli and mapping of the brain structures within a corresponding sensory pathway has been demonstrated (Bissig and Berkowitz, 2009; Chuang et al., 2009; Yu et al., 2005). On one hand, these studies convincingly demonstrated successful application of MEMRI for functional brain mapping; on the other hand, the experimental design in all of these studies involved a passive exposure of an animal to sensory information over a relatively long time. For example, in one study mice were exposed to sound for $24 \mathrm{~h}$ (Yu et al., 2005), in another study rats were maintained in visually stimulating environment for 8 h (Bissig and Berkowitz, 2009). Such long periods of passive (and unavoidable) exposure to sensory stimulation may produce nonphysiological patterns of activations reflecting not only the prolonged stimulation but also stress responses (Florentino et al., 1988; Geber, 1966; Hartel and Hartel, 1960). In the present study, we tested rat voluntary behavior; the amount of running activity was not restricted by the experimenter, which makes, in our opinion, this experimental situation physiologically more natural. In addition, manganeseassociated toxicity in these studies cannot be completely eliminated as according to our results the systemic doses of $\mathrm{MnCl}_{2}$ in a range of $40-60 \mathrm{mg} / \mathrm{kg}$ produce robust adverse behavioral effects as expressed by voluntary running and feeding activity. Clearly, the "tolerance" threshold for manganese-induced toxicity may depend on the question in study and this threshold becomes lower with increasing complexity of behavior to be performed by an animal. Finally, the signs of abnormal behavior may not be readily detected by using a rather simple behavioral paradigm.

All in all, the manganese systemic administration via osmotic pump allows avoiding acute toxic effects by providing slow delivery rate. It should be noted that the availability of $\mathrm{Mn}^{2+}$ to map active brain areas during the constant slow release achieved with osmotic pumps is not the same than after acute administration (either after one or multiple injections). After acute injection, plasma levels of $\mathrm{Mn}^{2+}$ are transiently increased, and therefore, the levels in the brain's extracellular space. This means that there exists a preferred time window for $\mathrm{Mn}^{2+}$ to move from the extracellular to the intracellular compartment and map a functional activation. This time window in experiments with acute manganese administration coincides with the moment of worst side effects likely related to peripheral toxicity. Manganese delivery with osmotic pumps provides a constant pull of available $\mathrm{Mn}^{2+}$ in the extracellular space while avoiding undesired side effects.

Furthermore, continuous slow manganese delivery over prolonged time results in MRI-detectable cumulative $\mathrm{Mn}^{2+}$ concentration in the brain that was sufficient for functional imaging. The daily dose used in our study $(11.4 \mathrm{mg} / \mathrm{kg} / 24 \mathrm{~h})$ is in a good agreement with the safe daily manganese amount for laboratory rodents $(10 \mathrm{mg} / \mathrm{kg})$ recommended by the National Research Council (National Research Council (U.S.). Subcommittee on Laboratory Animal Nutrition, 1995). Taking this into account, applying higher delivery rates may not be favorable for behavioral studies. A higher cumulative concentration of manganese in the brain can be further achieved either by increasing the exposure time, or by manganese delivery directly to the parenchyma or to the CSF via osmotic pumps. The latter, being on one hand more invasive, on the other hand may allow avoiding transient adverse effects related to peripheral toxicity.

Our findings put forward a new class of experimental paradigms, in which manganese-exposed animals may freely behave in complex environments, or may learn to perform various degrees of cognitive behaviors over an extended period of time. Such experiments are less susceptible to the reduced temporal resolution of the MEMRI method, compared to that achieved with conventional methods, such as the MR imaging utilizing the blood-oxygen-level-dependent (BOLD) contrast mechanism. With MEMRI, the relevant temporal resolution is likely to be predominantly determined by the frequency of 
scanning, which in turn would be limited by factors, such as optimal maintenance and recovery from anesthesia, as well as general effects of manganese of the animals' physiology.

Functional mapping using MEMRI has a clear advantage with respect to other neuroimaging techniques: it is likely to reflect an integrated brain activity over time due to the differential and structure or network-specific trans-synaptic transport of manganese along the activated pathways. Many research fields can potentially benefit from such an "integrative" imaging technique, including those concentrating on development, learning and memory, aging or disease-dependent degeneration of neuronal pathways.

Further development of brain imaging techniques suitable for laboratory animals is essential as they are not only complements to human imaging studies, but they also permit simultaneous application of various invasive methods. Such an integrative experimental approach eventually brings a substantial new knowledge for better understanding of neural mechanisms underlying cognitive processes and complex behaviors.

\section{Acknowledgments}

This work was supported by Max-Planck Society (O.E.) and Human Frontier Science Program Organization (S.C.). We thank Dr. Helmut Merkle for construction of saddle RF coils.

\section{Appendix A. Supplementary data}

Supplementary data associated with this article can be found, in the online version, at doi:10.1016/j.neuroimage.2009.10.079.

\section{References}

Afonso, V.M., Eikelboom, R., 2003. Relationship between wheel running, feeding, drinking, and body weight in male rats. Physiol. Behav. 80, 19-26.

Alvestad, S., Goa, P.E., Qu, H., Risa, O., Brekken, C., Sonnewald, U., Haraldseth, O. Hammer, J., Ottersen, O.P., Haberg, A., 2007. In vivo mapping of temporospatial changes in manganese enhancement in rat brain during epileptogenesis. Neurolmage 38, 57-66.

Aoki, I., Naruse, S., Tanaka, C., 2004a. Manganese-enhanced magnetic resonance imaging (MEMRI) of brain activity and applications to early detection of brain ischemia. NMR Biomed. 17, 569-580.

Aoki, I., Wu, Y.J., Silva, A.C., Lynch, R.M., Koretsky, A.P., 2004b. In vivo detection of neuroarchitecture in the rodent brain using manganese-enhanced MRI. NeuroImage 22, 1046-1059.

Belke, T.W., 1997. Running and responding reinforced by the opportunity to run: effect of reinforcer duration. J. Exp. Anal. Behav. 67, 337-351.

Berkowitz, B.A., Roberts, R., Goebel, D.J., Luan, H., 2006. Noninvasive and simultaneous imaging of layer-specific retinal functional adaptation by manganese-enhanced MRI. Investig. Ophthalmol. Vis. Sci. 47, 2668-2674.

Berkowitz, B.A., Roberts, R., Luan, H., Bissig, D., Bui, B.V., Gradianu, M., Calkins, D.J., Vingrys, A.J., 2007. Manganese-enhanced MRI studies of alterations of intraretinal ion demand in models of ocular injury. Investig. Ophthalmol. Vis. Sci. 48, 3796-3804.

Bissig, D., Berkowitz, B.A., 2009. Manganese-enhanced MRI of layer-specific activity in the visual cortex from awake and free-moving rats. Neurolmage 44, 627-635.

Bock, N.A., Paiva, F.F., Nascimento, G.C., Newman, J.D., Silva, A.C., 2008a. Cerebrospinal fluid to brain transport of manganese in a non-human primate revealed by MRI. Brain Res. 1198, 160-170.

Bock, N.A., Paiva, F.F., Silva, A.C., 2008b. Fractionated manganese-enhanced MRI. NMR Biomed. 21, 473-478.

Bock, N.A., Kocharyan, A., Silva, A.C., 2009. Manganese-enhanced MRI visualizes V1 in the non-human primate visual cortex. NMR Biomed. 22, 730-736.

Burton, N.C., Guilarte, T.R., 2009. Manganese neurotoxicity: lessons learned from longitudinal studies in nonhuman primates. Environ. Health Perspect. 117, 325-332.

Calabresi, P., Ammassari-Teule, M., Gubellini, P., Sancesario, G., Morello, M., Centonze, D., Marfia, G.A., Saulle, E., Passino, E., Picconi, B., Bernardi, G., 2001. A synaptic mechanism underlying the behavioral abnormalities induced by manganese intoxication. Neurobiol. Dis. 8, 419-432.

Canals, S., Beyerlein, M., Keller, A.L., Murayama, Y., Logothetis, N.K., 2008. Magnetic resonance imaging of cortical connectivity in vivo. Neurolmage 40, 458-472.

Chuang, K.H., Lee, J.H., Silva, A.C., Belluscio, L., Koretsky, A.P., 2009. Manganese enhanced MRI reveals functional circuitry in response to odorant stimuli. NeuroImage 44, 363-372.

Conway, B.R., Moeller, S., Tsao, D.Y., 2007. Specialized color modules in macaque extrastriate cortex. Neuron 56, 560-573.
Dodd, C.A., Ward, D.L., Klein, B.G., 2005. Basal Ganglia accumulation and motor assessment following manganese chloride exposure in the C57BL/ 6 mouse. Int. J. Toxicol. 24, 389-397.

Dorman, D.C., Struve, M.F., Wong, B.A., Dye, J.A., Robertson, I.D., 2006. Correlation of brain magnetic resonance imaging changes with pallidal manganese concentrations in rhesus monkeys following subchronic manganese inhalation. Toxicol. Sci. 92, 219-227.

Drapeau, P., Nachshen, D.A., 1984. Manganese fluxes and manganese-dependent neurotransmitter release in presynaptic nerve endings isolated from rat brain. J. Physiol. 348, 493-510.

Eikelboom, R., Mills, R., 1988. A microanalysis of wheel running in male and female rats. Physiol. Behav. 43, 625-630.

Eriksson, H., Magiste, K., Plantin, L.O., Fonnum, F., Hedstrom, K.G., TheodorssonNorheim, E., Kristensson, K., Stalberg, E., Heilbronn, E., 1987. Effects of manganese oxide on monkeys as revealed by a combined neurochemical, histological and neurophysiological evaluation. Arch. Toxicol. 61, 46-52.

Eschenko, O., Canals, S., Simanova, I., Beyerlein, M., Logothetis, N.K., in press. Behavioral electrophysiological and histopathological consequences of systemic manganese administration in MEMRI. Magn Reson Imaging. 28.

Finkelstein, Y., Zhang, N., Fitsanakis, V.A., Avison, M.J., Gore, J.C., Aschner, M., 2008 Differential deposition of manganese in the rat brain following subchronic exposure to manganese: a T1-weighted magnetic resonance imaging study. Isr. Med. Assoc. J. 10, 793-798.

Florentino, A., Castro, A., Fuentes, J.A., 1988. High blood pressure induced by audiovisual stimulation in young rats: effect of antihypertensive agents. Clin. Exp. Hypertens. A. $10,873-885$.

Geber, W.F., 1966. Developmental effects of chronic maternal audiovisual stress on the rat fetus. J. Embryol. Exp. Morphol. 16, 1-16.

Goense, J.B., Ku, S.P., Merkle, H., Tolias, A.S., Logothetis, N.K., 2008. fMRI of the temporal lobe of the awake monkey at 7T. Neurolmage 39, 1081-1093.

Gwiazda, R., Lucchini, R., Smith, D., 2007. Adequacy and consistency of animal studies to evaluate the neurotoxicity of chronic low-level manganese exposure in humans. J. Toxicol. Environ. Health A. 70, 594-605.

Hartel, A., Hartel, G., 1960. Experimental study of teratogenic effect of emotional stress in rats. Science 132, 1483-1484.

Holschneider, D.P., Maarek, J.M.I., Yang, J., Harimoto, J., Scremin, O.U., 2003. Functional brain mapping in freely moving rats during treadmill walking. J. Cereb. Blood Flow Metab. 23, 925-932.

Holschneider, D.P., Yang, J., Sadler, T.R., Nguyen, P.T., Givrad, T.K., Maarek, J.M.I., 2006. Mapping cerebral blood flow changes during auditory-cued conditioned fear in the nontethered, nonrestrained rat. NeuroImage 29, 1344-1358.

Iversen, I.H., 1993. Techniques for establishing schedules with wheel running as reinforcement in rats. J. Exp. Anal. Behav. 60, 219-238.

Jordan, L.M., 1998. Initiation of locomotion in mammals. Ann. N.Y. Acad. Sci. 860, 83-93.

Kayser, C., Petkov, C.I., Augath, M., Logothetis, N.K., 2007. Functional imaging reveals visual modulation of specific fields in auditory cortex. J. Neurosci. 27, 1824-1835.

Keilholz, S.D., Silva, A.C., Raman, M., Merkle, H., Koretsky, A.P., 2006. BOLD and CBV weighted functional magnetic resonance imaging of the rat somatosensory system. pp. 316-324.

Kim, Y., 2004. High signal intensities on T1-weighted MRI as a biomarker of exposure to manganese. Ind. Health 42, 111-115.

Lee, J.H., Garwood, M., Menon, R., Adriany, G., Andersen, P., Truwit, C.L., Ugurbil, K., 1995. High contrast and fast three-dimensional magnetic resonance imaging at high fields. Magn. Reson. Med. 34, 308-312.

Lee, J.H., Silva, A.C., Merkle, H., Koretsky, A.P., 2005. Manganese-enhanced magnetic resonance imaging of mouse brain after systemic administration of $\mathrm{MnCl} 2$ : dosedependent and temporal evolution of T1 contrast. Magn. Reson. Med. 53, 640-648.

Lin, Y.J., Koretsky, A.P., 1997. Manganese ion enhances T1-weighted MRI during brain activation: an approach to direct imaging of brain function. Magn. Reson. Med. 38 378-388.

Maier, A., Wilke, M., Aura, C., Zhu, C., Ye, F.Q., Leopold, D.A., 2008. Divergence of fMR and neural signals in $\mathrm{V} 1$ during perceptual suppression in the awake monkey. Nat. Neurosci. 11, 1193-1200.

Mohammad, F.K., Faris, G.A., 2006. Behavioral effects of acute manganese chloride administration in chickens. Biol. Trace Elem. Res. 110, 265-273.

Murphy, V.A., Wadhwani, K.C., Smith, Q.R., Rapoport, S.I., 1991. Saturable transport of manganese(II) across the rat blood-brain barrier. J. Neurochem. 57, 948-954.

Nam, J., Kim, K., 2008. Abnormal motor function and the expression of striatal dopamine D2 receptors in manganese-treated mice. Biol. Pharm. Bull. 31, 1894-1897.

Narita, K., Kawasaki, F., Kita, H., 1990. Mn and Mg influxes through Ca channels of motor nerve terminals are prevented by verapamil in frogs. Brain Res. 510, 289-295.

National Research Council (U.S.). Subcommittee on Laboratory Animal Nutrition, 1995. Nutrient Requirements of Laboratory Animals, 4th rev. ed. National Academy of Sciences, Washington, D.C.

Newland, M.C., 1999. Animal models of manganese's neurotoxicity. Neurotoxicology 20, 415-432.

Newland, M.C., Weiss, B., 1992. Persistent effects of manganese on effortful responding and their relationship to manganese accumulation in the primate globus pallidus. Toxicol. Appl. Pharmacol. 113, 87-97.

Newland, M.C., Ceckler, T.L., Kordower, J.H., Weiss, B., 1989. Visualizing manganese in the primate basal ganglia with magnetic resonance imaging. Exp. Neurol. 106, 251-258.

Nguyen, P.T., Holschneider, D.P., Maarek, J.M., Yang, J., Mandelkern, M.A., 2004 Statistical parametric mapping applied to an autoradiographic study of cerebral activation during treadmill walking in rats. Neurolmage 23, 252-259. 
Normandin, L., Ann Beaupré, L., Salehi, F., St.-Pierre, A., Kennedy, G., Mergler, D. Butterworth, R.F., Philippe, S., Zayed, J., 2004. Manganese distribution in the brain and neurobehavioral changes following inhalation exposure of rats to three chemical forms of manganese. Neurotoxicology 25, 433-441.

Olanow, C.W., Good, P.F., Shinotoh, H., Hewitt, K.A., Vingerhoets, F., Snow, B.J., Beal, M.F., Calne, D.B., Perl, D.P., 1996. Manganese intoxication in the rhesus monkey: a clinical, imaging, pathologic, and biochemical study. Neurology 46, 492-498.

Op de Beeck, H.P., Deutsch, J.A., Vanduffel, W., Kanwisher, N.G., DiCarlo, J.J., 2008 stable topography of selectivity for unfamiliar shape classes in monkey inferior temporal cortex. Cereb. Cortex. 18, 1676-1694.

Palmer, J.T., de Crespigny, A.J., Williams, S., Busch, E., van Bruggen, N., 1999. Highresolution mapping of discrete representational areas in rat somatosensory cortex using blood volume-dependent functional MRI. NeuroImage 9, 383-392.

Pautler, R.G., 2004. In vivo, trans-synaptic tract-tracing utilizing manganese-enhanced magnetic resonance imaging (MEMRI). NMR. Biomed. 17, 595-601.

Paxinos, G., Watson, C., 2005. The rat brain in stereotaxic coordinates, 5th ed. Elsevie Academic Press, Amsterdam ; Boston.

Premack, D., Schaeffer, R.W., 1963. Some parameters affecting the distributional properties of operant-level running in rats. J. Exp. Anal. Behav. 6, 473-475.

Rabin, O., Hegedus, L., Bourre, J.M., Smith, Q.R., 1993. Rapid brain uptake of manganese (II) across the blood-brain barrier. J. Neurochem. 61, 509-517.

Rhodes, J.S., Garland Jr., T., Gammie, S.C., 2003. Patterns of brain activity associated with variation in voluntary wheel-running behavior. Behav. Neurosci. 117, 1243-1256.

Saleem, K.S., Pauls, J.M., Augath, M., Trinath, T., Prause, B.A., Hashikawa, T., Logothetis, N. K., 2002. Magnetic resonance imaging of neuronal connections in the macaque monkey. Neuron 34, 685-700.

Schwarz, A.J., Danckaert, A., Reese, T., Gozzi, A., Paxinos, G., Watson, C., Merlo-Pich, E.V. Bifone, A., 2006. A stereotaxic MRI template set for the rat brain with tissue class distribution maps and co-registered anatomical atlas: application to pharmacological MRI. NeuroImage 32, 538-550.
Sherwin, C.M., 1998. Voluntary wheel running: a review and novel interpretation. Anim. Behav. 56, 11-27.

Shukakidze, A., Lazriev, I., Mitagvariya, N., 2003. Behavioral impairments in acute and chronic manganese poisoning in white rats. Neurosci. Behav. Physiol. 33, 263-267.

Silva, A.C., Lee, J.H., Aoki, I., Koretsky, A.P., 2004. Manganese-enhanced magnetic resonance imaging (MEMRI): methodological and practical considerations. NMR Biomed. 17, 532-543.

Silva, A.C., Lee, JH. Wu, C.W Tucciarone, J., Pelled, G., Aoki, I., Koretsky, A.P., 2008. Detection of cortical laminar architecture using manganese-enhanced MRI. J. Neurosci. Methods 167, 246-257.

Spenger, C., Josephson, A., Klason, T., Hoehn, M., Schwindt, W., Ingvar, M., Olson, L., 2000. Functional MRI at 4.7 tesla of the rat brain during electric stimulation of forepaw, hindpaw, or tail in single- and multislice experiments. Exp. Neurol. 166, 246-253.

Takeda, A., 2003. Manganese action in brain function. Brain Res. Brain Res. Rev. 41, 79-87.

Van Camp, N., Peeters, R.R., Van der Linden, A., 2005. A comparison between blood oxygenation level-dependent and cerebral blood volume contrast in the rat cerebral and cerebellar somatosensoric cortex during electrical paw stimulation. J. Magn. Reson. Imaging 22, 483-491.

Watanabe, T., Radulovic, J., Spiess, J., Natt, O., Boretius, S., Frahm, J., Michaelis, T., 2004. In vivo 3D MRI staining of the mouse hippocampal system using intracerebral injection of $\mathrm{MnCl} 2$. NeuroImage 22, 860-867.

Watanabe, T., Radulovic, J., Boretius, S., Frahm, J., Michaelis, T., 2006. Mapping of the habenulo-interpeduncular pathway in living mice using manganese-enhanced 3D MRI. Magn. Reson. Imaging 24, 209-215.

Weber, R., Ramos-Cabrer, P., Wiedermann, D., van Camp, N., Hoehn, M., 2006. A fully noninvasive and robust experimental protocol for longitudinal fMRI studies in the rat. NeuroImage 29, 1303-1310.

Yu, X., Wadghiri, Y.Z., Sanes, D.H., Turnbull, D.H., 2005. In vivo auditory brain mapping in mice with Mn-enhanced MRI. Nat. Neurosci. 8, 961-968. 